\title{
Production of large metallocarbohedrene clusters using a pulsed arc cluster ion source
}

\author{
N. Blessing, S. Burkart, and G. Ganteför ${ }^{\mathrm{a}}$ \\ Fachbereich für Physik, Universität Konstanz, 78457 Konstanz, Germany
}

\begin{abstract}
The hypothesis of the existence of multi-cage structures of metallocarbohedrene clusters ("metcars") bases on the observation of certain magic numbers in the mass spectra corresponding to an excess of carbon atoms with respect to the bulk stochiometry (1:1 for TiC). E.g., the appearance of the magic number cluster $\mathrm{Ti}_{13} \mathrm{C}_{22}$ has been explained by assuming a double-cage structure. However, the same magic number can be assigned to a $3 \times 3 \times 3$ cube $\left(=\mathrm{Ti}_{13} \mathrm{C}_{14}\right)$ with 8 additional carbon atoms forming carbon dimers at the corners of the cube. We recorded mass spectra of $\mathrm{Ti}_{n} \mathrm{C}_{m}$ clusters using a pulsed arc cluster ion source with an additional annealing discharge. For the positive ions, $\mathrm{Ti}_{8} \mathrm{C}_{12}^{+}$is the major peak in the mass spectrum. For the anions, much larger clusters could be generated. The maxima of the larger $\mathrm{Ti}_{n} \mathrm{C}_{m}^{-}$clusters including $\mathrm{Ti}_{13} \mathrm{C}_{22}^{-}$are located at masses slightly above the fcc cubic shell closings. The shift can be explained by the bonding of additional $\mathrm{C}$ atoms at the corners of the cubes.
\end{abstract}

PACS. 36.40.Mr Spectroscopy and geometrical structure of clusters - 36.40.Wa Charged clusters

\section{Introduction}

Metallocarbohedrene clusters ("metcars") have attracted considerable attention since their discovery by Castleman and coworkers $[1,2]$. They found the $\mathrm{M}_{8} \mathrm{C}_{12}(\mathrm{M}=\mathrm{Ti}, \mathrm{Zr}$, $\mathrm{V}, \mathrm{Hf}, \mathrm{Nb}$ ) cluster to be a prominent "supermagic" cluster similar to $\mathrm{C}_{60}$ and proposed a structure for this cluster in which both metal and carbon atoms are present in the wall of a symmetric cage with 12 five-membered rings $\left(\mathrm{T}_{h}\right.$ symmetry) [1]. More recently, most theoretical [3-7] results agree on a tetrahedral structure with $\mathrm{T}_{d}$ symmetry. On the experimental side, it was not possible to distinguish between the two proposed structures by ion mobility experiments [8] and chemisorption reactivity studies $[9,10]$, but anion photoelectron spectra $[11,12]$ and a recent chemisorption experiment [13] support the prediction of $\mathrm{T}_{d}$ symmetry.

Even more interesting is the proposed growth pattern of larger metcars. Bulk TiC and $\mathrm{ZrC}$ have a cubic structure and small clusters of these materials might form microcristals. Accordingly, the appearance of magic numbers corresponding to the $3 \times 3 \times 3,4 \times 4 \times 4$ and $5 \times 5 \times 5$ nanocubes $\left(\mathrm{M}_{13} \mathrm{C}_{14}, \mathrm{M}_{32} \mathrm{C}_{32}, \mathrm{M}_{62} \mathrm{C}_{63}\right.$, respectively) can be expected. However, Wei et al. observed the magic numbers $\mathrm{M}_{13} \mathrm{C}_{21 / 23}, \mathrm{M}_{18} \mathrm{C}_{29}$ and $\mathrm{M}_{22} \mathrm{C}_{35}$ [14]. These clusters exhibit an excess of carbon atoms and the stability of these clusters has been explained by the assumption of a multicage structure completely different from the bulk cubic

${ }^{a}$ e-mail: gerd.gantefoer@uni-konstanz.de structure. Fascinating new bulk materials might by built from such multi-cage clusters.

To our knowledge there are no spectroscopic data beside mass spectra supporting the idea of a multi-cage structure of such carbon-rich clusters. For the negatively charged species, $\mathrm{Ti}_{13} \mathrm{C}_{22}^{-}$has been found to be a magic number cluster and it was possible to record a photoelectron spectrum of it [15]. The spectrum has been compared to calculated spectra assuming certain geometries and no agreement has been found with the proposed double-cage structure. Instead, the spectrum shows a reasonable similarity with the calculated one for a cubic $3 \times 3 \times 3$ structure $\left(=\mathrm{Ti}_{13} \mathrm{C}_{14}\right)$ with 8 additional carbon atoms located at the cube corners. Thus, the excess of carbon atoms is not explained by a new geometric structure, but by the assumption that the corners of a nanocristal are stabilized by the formation of carbon dimers. However, because of the uncertainty involved into the calculation of photoelectron spectra this comparison should be taken as a hint only and not as a full proof for the assumed structure.

To gain additional information about the geometric structure of larger metcars we have generated larger clusters using an additional annealing process. The clusters are produced in a PACIS $[16,17]$ and annealed in an additional discharge, which presumably results in a relaxation of the clusters into their ground state geometry [18]. We observe a progression of maxima which almost coincides with geometrical shell closings of cubic structures. The maxima show a shift to larger masses, which can be explained by additional carbon atoms adsorbed at the corners of the nanocristals. Since the $\mathrm{Ti}_{13} \mathrm{C}_{22}^{-}$cluster fits into 


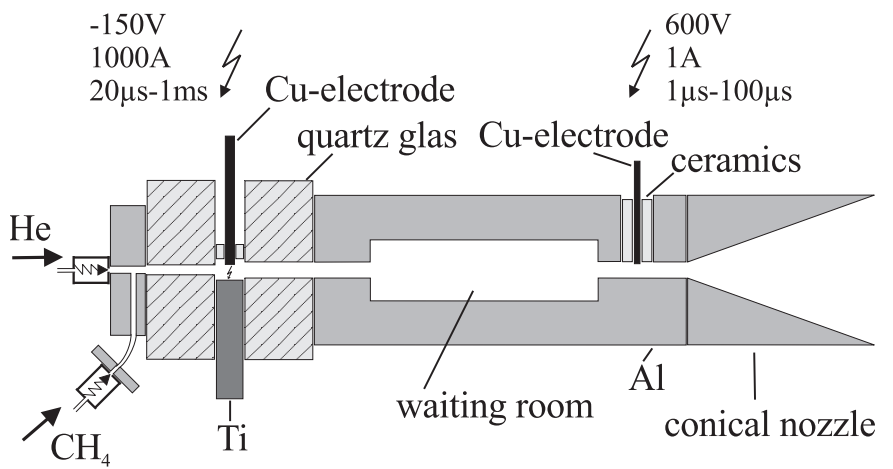

Fig. 1. Schematic presentation of the pulsed arc cluster ion source (PACIS; $[16,17])$ used for the generation of annealed metal-carbon cluster anions.

this progression, our data support the cubic structure proposed by Wang et al. [15].

\section{Cluster source}

Figure 1 shows a schematic presentation of the pulsed arc cluster ion source (PACIS) with an annealing stage used for the generation of positively and negatively charged large metcar clusters. A pulsed high current discharge (voltage: $\sim 150 \mathrm{~V}$, current: $\sim 1000 \mathrm{~A}$, duration $20-1000 \mu \mathrm{s}$ ) erodes material from a Ti cathode. A helium gas pulse supplied by a pulsed valve flushes the eroded material through a $10 \mathrm{~mm}$ long channel with a diameter of $3 \mathrm{~mm}$ into the "waiting room" tube. A variable amount of $\mathrm{CH}_{4}$ can be mixed with the helium using a second pulsed valve. The metal-carbon clusters grow in the waiting room. It has a diameter of $8 \mathrm{~mm}$ and a length of $120 \mathrm{~mm}$. At the end of the waiting room there is a second narrow channel with a length of $30 \mathrm{~mm}$ and a diameter of $4 \mathrm{~mm}$. Finally, the carrier gas flushes the clusters through a conical nozzle into vacuum.

At the end of the waiting room a pulsed weak discharge can be ignited by applying a high voltage pulse $(600 \mathrm{~V}$, 1 A) to an electrode located at the exit of the waiting room. For optimum yield of annealed ions, the timing (delay, duration) of the annealing discharge is crucial. In the process of discharge the preformed clusters are heated up again and may relax into their ground state geometry. Figure 2 demonstrates the annealing effect for carbon cluster anions, which are the predominant products generated at very high $\mathrm{CH}_{4}$ concentrations. Without the annealing, a smooth mass distribution is observed. Switching on the annealing alters the spectrum and the magic numbers of the fullerenes appear. In both spectra $\mathrm{C}_{n} \mathrm{H}_{m}^{-}$clusters with $m=1-4$ can also be observed, indicating incomplete dehydrogenation.

\section{Mass spectra}

We measured time-of-flight mass spectra of ions directly produced by the PACIS. No further ionization or electron attachment has been used. For the optimum yield

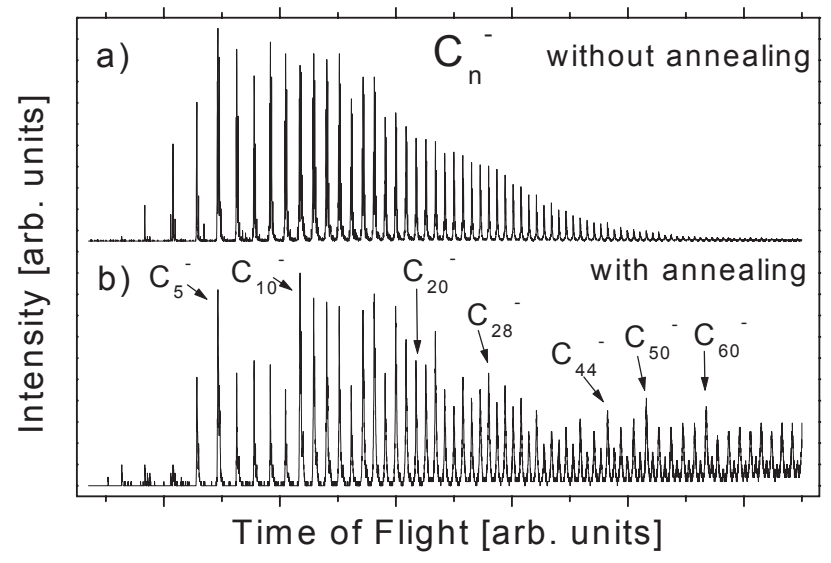

Fig. 2. Carbon cluster anions directly produced with the PACIS as shown in Figure 1 and operating at high $\mathrm{CH}_{4}$ concentrations. With the annealing discharge switched on, carbon fullerenes with the magic clusters $\mathrm{C}_{44}^{-}, \mathrm{C}_{50}^{-}$and $\mathrm{C}_{60}^{-}$appear.

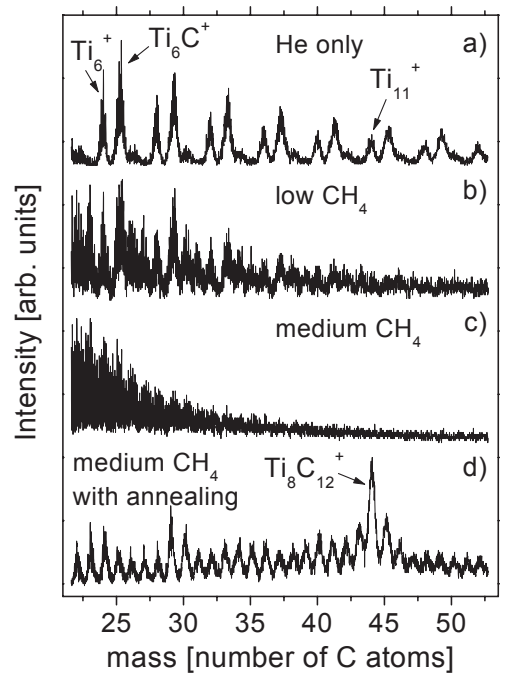

Fig. 3. (a) Section of a time-of-flight mass spectrum of $\mathrm{Ti}_{n}^{+}$ clusters with bare $\mathrm{He}$ as a carrier gas. The high intensity of $\mathrm{Ti}_{n} \mathrm{C}_{1}^{+}$clusters is due to residual carbon in the source. (b) Same as (a), but obtained with a small amount of $\mathrm{CH}_{4}$ in the $\mathrm{He}$ carrier gas. The main peaks are assigned to $\mathrm{Ti}_{n} \mathrm{C}_{1} \mathrm{H}_{m}^{+}$clusters with $m=1-4$. (c) Same as (a), but obtained with a medium concentration of $\mathrm{CH}_{4}$ in the He carrier gas. (d) Same as (c), but with the annealing discharge switched on.

of cations, a smaller waiting room (diameter: $5 \mathrm{~mm}$, length: $40 \mathrm{~mm}$ ) has been used. Figure 3a displays a section of a mass spectrum of $\mathrm{Ti}_{n}^{+}$cluster cations using pure He as carrier gas. The mass resolution of the time-of-flight spectrometer is $m / \Delta m=400$ and the widths of the peaks assigned to certain clusters correspond to the isotope distribution of Ti. Due to residual carbon in the source the $\mathrm{Ti}_{n} \mathrm{C}_{1}^{+}$clusters have a higher intensity than the bare $\mathrm{Ti}_{n}^{+}$ clusters. In Figure $3 \mathrm{~b}$ a small amount of $\mathrm{CH}_{4}$ is added to the carrier gas. Several mixed clusters consisting of Ti, C and $\mathrm{H}$ atoms can be observed with the maximum intensity for $\mathrm{Ti}_{n} \mathrm{C}_{1} \mathrm{H}_{m}^{+}(m=0-3)$ clusters. At a higher relative concentration of $\mathrm{CH}_{4}$ (Fig. 3c) the mass spectrum displays a 


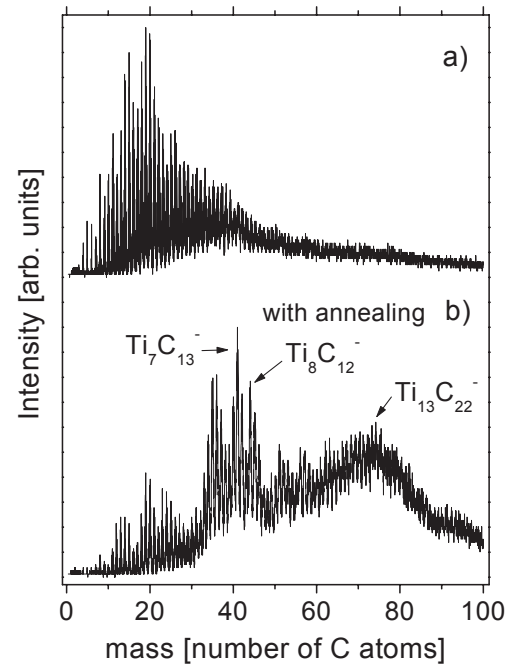

Fig. 4. Comparison of mass spectra of $\mathrm{Ti}_{n} \mathrm{C}_{m}$ cluster anions with the annealing discharge switched off (a) and on (b).

structureless continuum of peaks. Figure 3d displays the mass spectrum obtained under similar conditions as in Figure 3c, but with the annealing discharge switched on. The spectrum alters dramatically. One change is the shift of intensity to larger masses. A similar effect was observed previously for pure carbon clusters [18]. Now, the peak assigned to $\mathrm{Ti}_{8} \mathrm{C}_{12}^{+}$is prominent, in agreement with mass spectra of metal-carbon cluster cations obtained with a laser vaporization source $[1,2]$.

For the generation of negatively charged metcars, different source conditions have been applied. Especially, the larger "waiting room" displayed in Figure 1 was inserted. Figure 4 shows two examples of mass spectra of metalcarbon cluster anions obtained with this source design. In both spectra a medium concentration of $\mathrm{CH}_{4}$ has been supplied resulting in the growth of $\mathrm{Ti}_{n} \mathrm{C}_{m}^{-}$clusters with various combinations of $n$ and $m$. The pattern of equally spaced mass peaks results from the fact that the mass of 4 carbon atoms equals the mass of one Ti atom.

The anion spectrum alters dramatically, if the annealing discharge is switched on (Fig. 4b). In agreement with anion mass spectra generated with a laser vaporization source [15] two groups of intense lines around $\mathrm{Ti}_{7} \mathrm{C}_{13}^{-}$and $\mathrm{Ti}_{13} \mathrm{C}_{22}^{-}$can be observed. We confirmed the assignments of the peaks by recording corresponding photoelectron spectra [19]. The peak assigned to $\mathrm{Ti}_{8} \mathrm{C}_{12}^{-}$is a local maximum, but in contrast to the spectrum of the cations it is not a prominent peak and even smaller than the one assigned to $\mathrm{Ti}_{7} \mathrm{C}_{13}^{-}$. If the high relative stability of the $\mathrm{Ti}_{8} \mathrm{C}_{12}$ cluster is related to the geometric structure, it should be independent of the charge state and the $\mathrm{Ti}_{8} \mathrm{C}_{12}^{-}$anion should appear as a "magic" peak similar to $\mathrm{C}_{60}^{-}[18]$. However, this is not the case, and, according to a study by Wang's group, $\mathrm{Ti}_{8} \mathrm{C}_{12}^{-}$can even be totally absent under certain conditions [20]. Using the PACIS source, $\mathrm{Ti}_{8} \mathrm{C}_{12}^{-}$is always observed in the mass spectrum, but its intensity relative to $\mathrm{Ti}_{7} \mathrm{C}_{13}^{-}$depends on the source conditions. We agree with the explanation for the low intensity of $\mathrm{Ti}_{8} \mathrm{C}_{12}^{-}$proposed

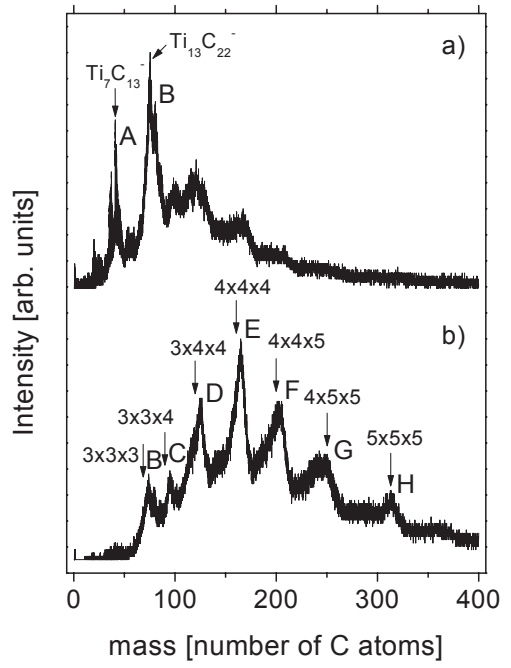

Fig. 5. Comparison of two different mass spectra of $\mathrm{Ti}_{n} \mathrm{C}_{m}^{-}$ clusters obtained with the PACIS displayed in Figure 1. The source conditions have been optimized for the generation of small (a) and large (b) metcars. The maximum marked B appears in both spectra.

by Wang and coworkers $[15,20]$ : the low electron affinity of $\mathrm{Ti}_{8} \mathrm{C}_{12}^{-}$might be responsible for the surprisingly low abundance of these anions and, therefore, its low abundance might not be related to its stability.

The observation of geometrical shell closings of considerably larger metal-carbon clusters will allow us to distinguish between different growth patterns proposed for metcars. With the design of the PACIS displayed in Figure 1 it is possible to generate $\mathrm{Ti}_{n} \mathrm{C}_{m}^{-}$clusters up to a mass equivalent to the one of the $5 \times 5 \times 5$ cube $\left(\mathrm{Ti}_{62} \mathrm{C}_{63}\right)$. Figure 5 a displays a mass spectrum of $\mathrm{Ti}_{n} \mathrm{C}_{m}^{-}$cluster anions generated under optimum conditions for the generation of small metcars. The spectrum is very similar to the one recorded by Wang's group [15]. It is basically similar to one displayed in Figure $4 \mathrm{~b}$ and the differences between the two spectra are due to small changes in the timing of the annealing discharge. The spectrum is dominated by two features centering on the prominent peaks $\mathrm{Ti}_{7} \mathrm{C}_{13}^{-}$ (marked A) and $\mathrm{Ti}_{13} \mathrm{C}_{22}^{-}$(marked $\mathrm{B}$ ). Keeping the adjustments of the mass spectrometer constant, the source in Figure $5 \mathrm{~b}$ is tuned to produce larger clusters of anions. Compared to Figure 5 a the group of peaks around $\mathrm{Ti}_{7} \mathrm{C}_{13}^{-}$ (A) vanishes, but the main peak B observed in Figure $5 \mathrm{a}$ assigned to $\mathrm{Ti}_{13} \mathrm{C}_{22}^{-}$can still be observed with reduced intensity. The small feature at slightly larger mass assigned to $\mathrm{Ti}_{14} \mathrm{C}_{24}^{-}$[15] is still visible, too, and from this similarity we conclude that the two features marked B in Figures 5a and $5 \mathrm{~b}$ have the same origin and that the corresponding $\mathrm{Ti}_{13} \mathrm{C}_{22}^{-}$clusters probably have identical structures.

\section{Discussion}

In Figure 5b with peak $\mathrm{B}$ a new progression of maxima (marked B-H) starts which may correspond to geometric shell closings. Table 1 displays the masses corresponding 
Table 1. Comparison of the positions of maxima observed in the mass spectrum of the $\mathrm{Ti}_{n} \mathrm{C}_{m}^{-}$cluster anions (Fig. 5b) with the shell closings predicted by different models for the growth patterns of metcars ("multi-cages" [10]; "cubic fcc structures" $[12,20]$; "quantum wires" [15]). The mass is given in numbers of corresponding carbon atoms $(1 \mathrm{Ti}$ atom $=$ $4 \mathrm{C}$ atoms).

\begin{tabular}{ccccc}
\hline peak & exp. mass & multi-cages & cubic fcc & quantum wires \\
\hline B & 74 & 74 (double) & $66(3 \times 3 \times 3)$ & 74 \\
C & $96 \pm 2$ & 101 (triple) & $90(3 \times 3 \times 4)$ & 98 \\
D & $126 \pm 3$ & 123 (quad.) & $120(3 \times 4 \times 4)$ & 123 \\
E & $166 \pm 3$ & - & $160(4 \times 4 \times 4)$ & 147 \\
F & $207 \pm 4$ & - & $200(4 \times 4 \times 5)$ & 172 \\
G & $249 \pm 6$ & - & $250(4 \times 5 \times 5)$ & 196 \\
H & $316 \pm 5$ & - & $311(5 \times 5 \times 5)$ & 221 \\
\hline
\end{tabular}

to the maxima observed in Figure $5 \mathrm{~b}$ given in numbers of carbon atoms ( $1 \mathrm{Ti}$ atom has a mass of 4 carbon atoms). In addition, the shell closings as predicted from the different growth models are given. We consider three different growth patterns, which have been discussed in the literature:

(i) "multi-cages" [10],

(ii) "cubic fcc structures" $[12,20]$ and

(iii) "quantum wires" [15].

The distances between the shell closings observed in Figure 5b increase in mass. This excludes the "multicages" and the "quantum wires" approaches, because for these two growth patterns the differences in mass between two successive shell closings would either decrease ("multicages") or stay constant ("quantum wires").

The increasing mass between successive shell closings which can be observed experimentally coincides approximately with the cubic fcc shell closings (indicated by arrows in Fig. 5b). Peak B correspond to the $3 \times 3 \times 3$ cube, feature $\mathrm{E}$ to the $4 \times 4 \times 4$ cube and the last resolved maximum to the $5 \times 5 \times 5$ cube. The other maxima probably correspond to the closings of subshells (like feature G: $4 \times 5 \times 5)$. This assignment is supported by the observation that features assigned to symmetric cubes are relatively sharp compared to the maxima assigned to subshells, which have a step-like broad shape.

The maxima are shifted to slightly larger values compared to the expected positions of the cubic shell closings. We assume that these cubic structures have additional atoms bound at the corners of the cubes. Such a structure has been proposed for the $\mathrm{Ti}_{13} \mathrm{C}_{22}^{-}$cluster [15]. E.g., the $3 \times 3 \times 3$ cube corresponding to the $\mathrm{Ti}_{13} \mathrm{C}_{14}$ cluster might be stabilized by 8 additional $\mathrm{C}$ atoms forming carbon dimers at the corners of the cube resulting in a shell closing at $\mathrm{Ti}_{13} \mathrm{C}_{22}$. Within the range of uncertainty of our experiment, all observed shell closings coincide with cubic fcc shell closings shifted by $6 \pm 2 \mathrm{C}$ atoms.

This analysis supports the structure proposed by Wang et al. for the $\mathrm{Ti}_{13} \mathrm{C}_{22}^{-}$cluster [15] (but contradicts the "quantum wire" growth pattern proposed in the same publication). Shell closings observed in other mass spectra [10], which have been assigned to multi-cages, might also be explained using our approach of cubic structures stabilized by additional atoms. The number of additional atoms can by different for different shell closings. E.g., for nanocristals other than the $3 \times 3 \times 3\left(\mathrm{Ti}_{13} \mathrm{C}_{22}\right)$ and $5 \times 5 \times 5\left(\mathrm{Ti}_{62} \mathrm{C}_{63}\right)$ cubes half of the corners are occupied by $\mathrm{Ti}$ atoms and the formation of carbon dimers by the adsorption of one additional carbon atom is not possible. These clusters might undergo a more complex structural change to enable the formation of a maximum number of carbon dimers. The process can be viewed in terms of surface physics as an adsorbate (i.e., carbon) induced reconstruction. The cluster is stabilized by the adsorption of additional carbon atoms.

The magic numbers observed in the mass spectra depend on the growths conditions in the different cluster sources. At certain source adjustments [21-23] maxima corresponding to cubic bulk-like structures are observed (e.g., $\mathrm{Ti}_{13} \mathrm{C}_{14}[24]$ ). If the conditions are altered, different magic numbers with higher carbon content appear (e.g., $\mathrm{Nb}_{13} \mathrm{C}_{22}$ [25]), which have been assigned to multicage structures [14]. According to our data, a different interpretation of the latter observations is possible: at low carbon concentration in the source the bare nanocristals are generated (e.g., $\mathrm{Ti}_{13} \mathrm{C}_{14}$ ), while at higher carbon concentration the crystals are stabilized by the adsorption of additional carbon atoms $\left(\mathrm{Ti}_{13} \mathrm{C}_{22}\right)$. However, the underlying structure is still cubic fcc-like.

\section{Conclusion}

We describe the generation of large $\mathrm{Ti}_{n} \mathrm{C}_{m}$ clusters using a pulsed arc cluster ion source with an additional weak annealing discharge, which especially has been optimized for the generation of high intensities of such clusters. In the mass spectrum of annealed negatively charged metcar clusters a series of maxima is observed starting at the $\mathrm{Ti}_{13} \mathrm{C}_{22}^{-}$cluster. Probably the maxima correspond to geometric shell closing and are compared to predictions of three different possible structures of these clusters: multicages, cubic fcc and quantum wires. The experimental data agree well with the assumption of a cubic fcc structure with an excess of 8 carbon atoms forming carbondimers at the corners of the cubes. The $\mathrm{Ti}_{13} \mathrm{C}_{22}$ cluster is the smallest species belonging to this series and can be assigned to the $3 \times 3 \times 3$ nanocube with 8 additional carbon atoms as suggested in reference [15]. However, further spectroscopic data like the ones presented in reference [23] for the bulk-like $\mathrm{Ti}_{14} \mathrm{C}_{13}$ are necessary to gain more information about the structure of these very interesting clusters.

\section{References}

1. B.C. Guo, K.P. Kerns, A.W. Castleman Jr, Science 255, 1411 (1992). 
2. B.C. Guo, S. Wei, J. Purnell, S. Buzza, A.W. Castleman Jr, Science 256, 511 (1992).

3. I. Dance, J. Chem. Soc. Chem. Commun. 1992, 1779 (1992).

4. I. Dance, J. Am. Chem. Soc. 118, 6309 (1996).

5. M.M. Rohmer, M. Benard, C. Henriet, C. Bo, J.M. Poblet, J. Chem. Soc. Chem. Commun. 1993, 1182 (1993).

6. M.M. Rohmer, C. Bo, J.M. Poblet, J. Am. Chem. Soc. 117, 508 (1995).

7. J. Munoz, M.-M. Rohmer, M. Benard, C. Bo, J.-M. Poblet, J. Phys. Chem. A 103, 4762 (1999) and references therein.

8. S. Lee, N.G. Gotts, G. von Helden, M.T. Bowers, Science 267, 999 (1995).

9. B.C. Guo, K.P. Kerns, A.W. Castleman Jr, J. Am. Chem. Soc. 115, 7415 (1993).

10. C.S. Yeh, S. Afzaal, S.A. Lee, Y. Buyun, B.S. Freiser, J. Am. Chem. Soc. 116, 8806 (1994).

11. L.S. Wang, S. Li, H. Wu, J. Phys. Chem. 100, 19211 (1996).

12. S. Li, H. Wu, L.S. Wang, J. Am. Chem. Soc. 119, 7417 (1997).

13. H. Sakurai, A.W. Castleman Jr, J. Chem. Phys. 111, 1462 (1999).
14. S. Wei, B.C. Guo, J. Purnell, S. Buzza, A.W. Castleman Jr, Science 265, 818 (1992).

15. L.-S. Wang, H.S. Cheng, Phys. Rev. Lett. 78, 2983 (1997).

16. G. Ganteför, H.R. Siekmann, H.O. Lutz, K.H. MeiwesBroer, Chem. Phys. Lett. 165, 293 (1990).

17. Chia-Yen Cha, G. Ganteför, W. Eberhardt, Rev. Sci. Instrum. 63, 5661 (1992).

18. H. Handschuh, G. Ganteför, B. Kessler, P.S. Bechthold, W. Eberhardt, Phys. Rev. Lett. 74, 1095 (1995).

19. S. Burkart, N. Blessing, G. Ganteför, D. Kreisle, to be published.

20. L.-S. Wang, X.-B. Wang, H.B. Wu, H.S. Cheng, J. Am. Chem. Soc. 120, 6556 (1998).

21. J.S. Pilgrim, M.A. Duncan, J. Am. Chem. Soc. 115, 9724 (1993).

22. J.S. Pilgrim, L.R. Brock, M.A. Duncan, J. Phys. Chem. 99, 544 (1995).

23. D.v. Heijnsbergen, G.v. Helden, M.A. Duncan, A.J.A. van Roij, G. Meijer, Phys. Rev. Lett. 83, 4983 (1999).

24. A. Khan, J. Phys. Chem. 99, 4923 (1995).

25. S. Wei, B.C. Guo, H.T. Deng, K. Kerns, J. Purnell, S.A. Buzza, A.W. Castleman Jr, J. Am. Chem. Soc. 116, 4475 (1994). 